Acta Theriologica 45 (4): 455-470, 2000.

PL ISSN 0001-7051

\title{
Individual variation and repeatability of maximum cold-induced energy assimilation in house mice
}

\author{
Paweł KOTEJA, John G. SWALLOW ${ }^{1}$, Patrick A. CARTER ${ }^{2}$ \\ and Theodore GARLAND Jr
}

Koteja P., Swallow J. G., Carter P. A. and Garland T. Jr 2000. Individual variation and repeatability of maximum cold-induced energy assimilation in house mice. Acta Theriologica 45: 455-470.

Maximum cold-induced rate of food consumption in cold-acclimated laboratory house mice Mus domesticus averaged $10.4 \mathrm{~g} /$ day in females (body mass before cold exposure $=25.2 \mathrm{~g}$ ) and $10.7 \mathrm{~g} /$ day in males (body mass $=31.7 \mathrm{~g}$ ); corresponding maximum rates of energy assimilation were $139 \mathrm{~kJ} /$ day in females and $144 \mathrm{~kJ} /$ day in males. The traits were highly repeatable: the intraclass correlation coefficient for three trials at $-10^{\circ} \mathrm{C}$ was greater than 0.7 for absolute values and greater than 0.6 for values independent of the initial body mass (residuals from ANCOVA). The estimate of repeatability of the mass-independent traits depends on which estimate of body mass (initial or after cold exposure) is used as a covariate in the regression or ANCOVA model. We conclude that the values of maximum cold-induced food consumption and energy assimilation are reliable estimates of the performance of individuals under a specific set of environmental conditions (low ambient temperature, but not limited access to food) and hence may be subject to phenotypic natural or artificial selection.

Institute of Environmental Sciences, Jagiellonian University, ul. Ingardena 6, 30-060 Kraków, Poland, e-mail: koteja@eko.uj.edu.pl (PK); Department of Zoology, 430 Lincoln Drive, University of Wisconsin-Madison, Madison, WI 53706, USA (JGS, PAC, TG)

Key words: Mus domesticus, ecological physiology, energetics, quantitative genetics

\section{Introduction}

Over the past two decades, ecological physiology has become increasingly focused on inter-individual variation, rather than only considering average values for populations or species (Garland and Carter 1994, Bennett 1997, Hayes and Jenkins 1997, Kolok 1999). Evolutionary inferences about phenotypic variation generally require that the trait in question is heritable in the narrow sense. A

\footnotetext{
Present addresses:

${ }^{1}$ Department of Zoology, University of Maryland, College Park, MD 20742, USA

${ }^{2}$ Department of Zoology, Washington State University, Pullman, WA 99164, USA
} 
minimum, although not sufficient, requirement for heritability is significant repeatability of the trait measurement. The value of repeatability provides an estimate of maximum theoretical heritability, and can serve as a guide in interpretation of results and planning further research (Boake 1989, Falconer and Mackay 1996, Hayes and Jenkins 1997). The aim of this study was to measure repeatability of the maximum cold-induced rate of food consumption and energy assimilation in laboratory house mice Mus domesticus.

In vertebrate ecological energetics, estimates of repeatability have been obtained for maximum oxygen consumption during forced exercise and cold exposure, and for basal metabolic rate (Garland and Else 1987, Hayes 1989a, b, Garland and Bennett 1990, Hayes and Chappell 1990, Hayes et al. 1992, Dohm 1994, Chappell et al. 1995, Chappell et al. 1996, Hayes and O'Connor 1999). These studies provided evidence of moderate to high repeatability of the traits, at least when measured over short time intervals. On the other hand, repeatability of daily energy expenditure (DEE) measured with a doubly labeled water method in two species of rodents was relatively low (Speakman et al. 1994, Berteaux et al. 1996). Moreover, these authors demonstrated that the repeatability of DEE was low not because of errors in methods or instruments, but because energy expenditures of individuals varied substantially between consecutive days. Berteaux et al. (1996) concluded that "Future studies of repeatability of FMR [field metabolic rate] should concentrate on energetically demanding periods, such as those under cold-stress; this may allow for the detection of individual differences, which we presume are the basis of natural selection".

In laboratory experiments with small mammals, upper limits to energy budgets have been estimated as a maximum rate of food consumption $\left(\mathrm{C}_{\max }\right)$ or energy assimilation $\left(\mathrm{A}_{\mathrm{max}}\right)$, measured during cold-exposure or at the peak of lactation (see reviews: Weiner 1989, 1992, Karasov 1990, Peterson et al. 1990, Hammond and Diamond 1997). Several of the experiments were explicitly designed to study individual variation of $\mathrm{C}_{\max }$ and $\mathrm{A}_{\max }$ and their correlation with other physiological or morphological traits (eg Hammond and Diamond 1994, Hammond et al. 1994, Konarzewski and Diamond 1994, Koteja et al. 1994, Koteja 1995, 1996b, Speakman and McQueenie 1996). To our knowledge, however, no attempts to estimate the repeatability of $\mathrm{A}_{\max }$ or $\mathrm{C}_{\max }$ have been undertaken.

Estimating the repeatability of cold-induced $\mathrm{C}_{\max }$ or $\mathrm{A}_{\max }$ is difficult because the measurement itself can change the physiology and morphology of the individual tested. A few days of cold exposure, which is necessary for a reliable estimation of energy assimilation, is enough to increase the capacity for thermogenesis, capacity of the alimentary tract, and maximum energy assimilation rate (eg Weiner 1987, Hayes and Chappell 1990, Koteja 1996b). Therefore, two consecutive trials at low temperature will usually yield different results, and may actually represent distinct traits: $\mathrm{A}_{\max }$ of a non-acclimated individual, and that of a cold-acclimated one. One solution to the problem could be performing the consecutive measurements after a long time, to allow a reversal of the acclimation. Another solution, applied in this 
study, is to perform several consecutive trials at low temperature, to achieve a full cold-acclimation, and use the data from the final trials to estimate repeatability in cold-acclimated individuals.

\section{Material and methods}

\section{Animals}

Outbred, genetically variable Hsd:ICR mice (Hauschka and Mirand 1973, Rice and O'Brien 1980, Dohm et al. 1996, Carter et al. 1999) were used to establish eight lines in 1993: four selected for high voluntary wheel running and four randomly bred (controls). See Swallow et al. (1998a) and Koteja et al. (1999a, b) for details of animal maintenance and the selection protocol. In this paper, we will not discuss possible effects of the artificial selection and variation among the lines; instead, we will treat the effects as an additional source of variation, to be controlled statistically.

We used 146 individuals from generation 10 post-selection (second litters). Mice were housed individually from weaning in cages equipped with wheels (see Swallow et al. 1998b for a report on wheel running and exercise metabolism in siblings of the mice used here). In the first part of the experiment, reported by Koteja et al. (1999b), food consumption and energy assimilation were measured at $22^{\circ} \mathrm{C}$ in cages with and without wheels. The cold-exposure trials began when the mice were $76-92$ (average 88) days old. To avoid peripheral injury from frostbite, we cropped tips of the ears and tails of anesthetized (Metofane) mice 7 weeks before the cold-exposure trials (as in Konarzewski and Diamond 1994). No postoperative complications occurred.

\section{Protocol}

Rates of food consumption and energy assimilation were measured in plastic mouse cages $(27 \times 17$ $\times 12.5 \mathrm{~cm}$; wire tops) with perforated polypropylene plates suspended over the floor. No nesting material was provided. Grids were placed in the cages 22 days before the first cold exposure. Trials were performed consecutively, so that the end of one trial was the start of the next, as follows (Fig. 1): (1) Three days at $-5^{\circ} \mathrm{C}$, without prior acclimation. (2) Sixteen days at $+5^{\circ} \mathrm{C}$, to allow cold acclimation. Energy assimilation was measured during the first 3 days (one trial) and during the last 7 days (two trials). (3) Twelve days at $-5^{\circ} \mathrm{C}$. Energy assimilation was measured during the first and during the last 3 days (two trials). (4) Fourteen days at $-10^{\circ} \mathrm{C}$. Energy assimilation was measured during the first 6 days (two trials) and during the last 3 days (one trial). (5) Two days at $-15^{\circ} \mathrm{C}$ (one trial).

The temperatures were chosen based on results of Konarzewski and Diamond (1994) and on results of pilot trials performed with our mice, which indicated that non-acclimated individuals could not maintain body mass at $-8^{\circ} \mathrm{C}$. Measurements were performed simultaneously on all individuals. Cages were grouped on two racks, each with four levels of shelves; racks were placed in a thermoregulated walk-in chamber (photoperiod 12L:12D). To protect the animals from direct streams of cold air produced by the cooling system, we covered the entire racks with transparent PVC curtains. We could not, however, avoid a stratification of temperature under the cover (up to $2^{\circ} \mathrm{C}$ differences between top and bottom shelves). Therefore, position of the cages in the chamber (rack, shelf) was used as a cofactor in statistical analyses (see below).

\section{Food consumption and energy assimilation}

At the beginning of each trial, animals were weighed $( \pm 0.1 \mathrm{~g})$ and a weighed portion of food $( \pm 0.01 \mathrm{~g}$, Harlan Teklad Laboratory Rodent Diet [W] 8604) was provided. Water was available ad libitum; at sub-zero temperatures, ice cubes were provided. Samples of the food were taken to measure dry mass content. After each trial the cages were changed. Uneaten food and feces were collected, 

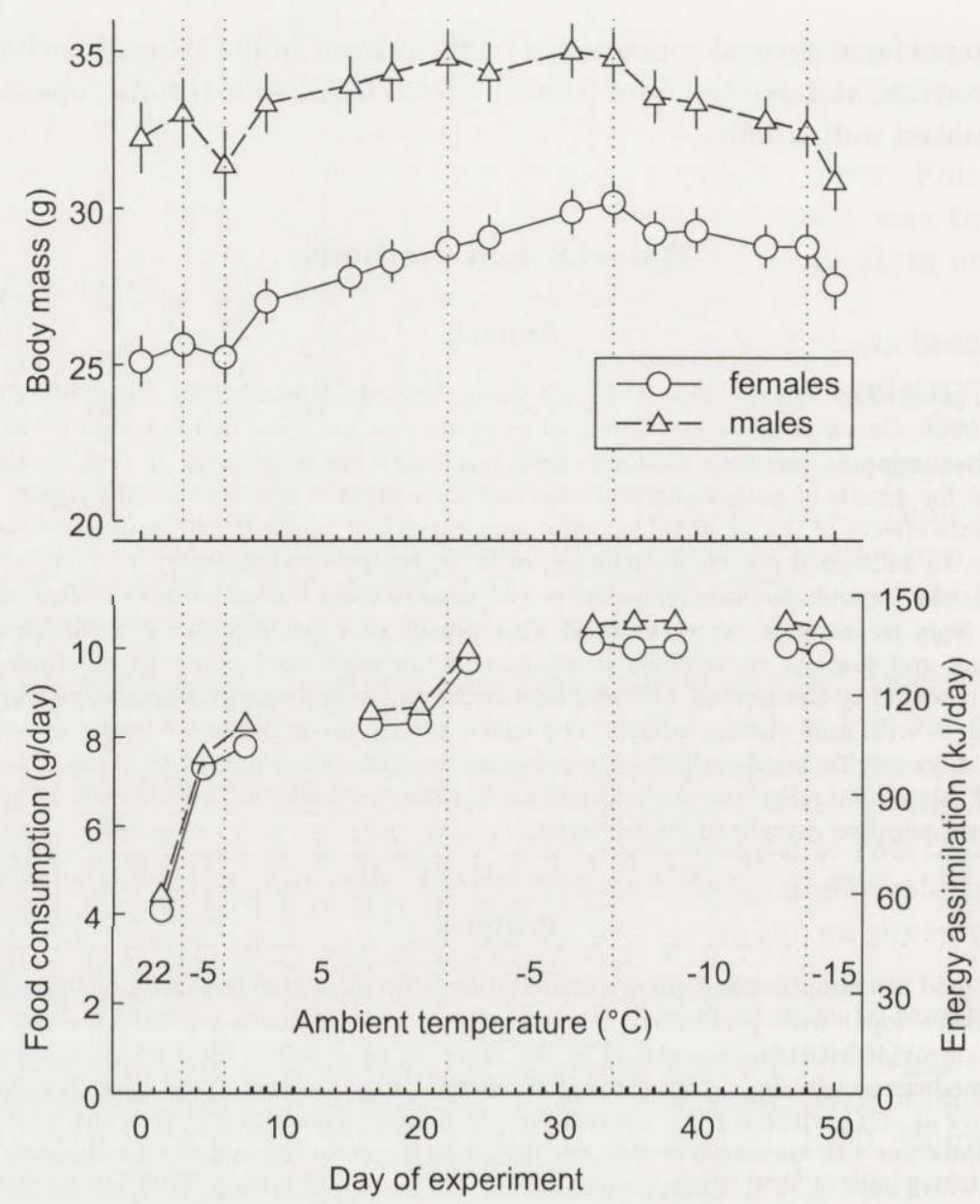

Fig. 1. Changes in body mass (top) and the rate of food consumption and energy assimilation (bottom) in cold-exposed laboratory house mice. The symbols indicate average values $\pm 2 \mathrm{SE}$ (the symbols completely overlap the $\pm 2 \mathrm{SE}$ range for food consumption). The gaps in the lines in bottom panel indicate periods when food consumption was not measured.

segregated manually, and dried at $60^{\circ} \mathrm{C}$ to constant mass. Energy content of dry food $\left(\mathrm{E}_{\text {food }}=\right.$ $17.73 \mathrm{~kJ} / \mathrm{g}$ dry mass) and feces $\left(\mathrm{E}_{\text {feces }}=14.93 \mathrm{~kJ} / \mathrm{g}\right.$ dry mass) was measured with a Phillipson Microbomb Calorimeter (Gentry Instruments, Inc.). We sampled the feces from one male and one female from each line in three trials (room temperature, first cold exposure, and $-10^{\circ} \mathrm{C}$ after cold exposure; a total of 48 samples), and used an average value in further calculations (ANOVA indicated no significant differences between trials, sexes or lines).

Food consumption rate $(\mathrm{C}, \mathrm{g} /$ day), energy assimilation (A, kJ/day), and coefficients of digestibility of dry mass $\left(\mathrm{d}_{\mathrm{m}}, \%\right)$ and of energy $\left(\mathrm{d}_{\mathrm{e}}, \%\right)$ were calculated according to Drożdż (1975) and Koteja et al. (1999b). To calculate the rate of energy assimilation, we assumed 3\% of energy loss in urine (Drożdż 1975). 


\section{Statistical analysis}

Repeatability of the traits measured $\left(\mathrm{A}_{\max }, \mathrm{C}_{\max }\right.$, and digestibility) was evaluated in two ways (Hayes and Jenkins 1997). First, we calculated the intraclass correlation coefficient $\left(r_{i}\right.$; Sokal and Rohlf 1981, Lessells and Boag 1987), based on a one-way ANOVA with individuals as a group variable (among-individual variance component) and three measurements at $-10^{\circ} \mathrm{C}$ as replicates (within-individual variance component). The coefficient calculated in this way is a measure of repeatability as defined in quantitative genetics (Falconer and Mackay 1996, Hayes and Jenkins 1997). Second, we calculated the Pearson product-moment correlation coefficient $\left(r_{\mathrm{P}}\right)$ between the highest value of food consumption or energy assimilation achieved by an individual $\left(\mathrm{C}_{\max }, \mathrm{A}_{\max }\right)$ and the value obtained in the next or previous trial, depending on data availability $\left(A_{\text {near }}, C_{\text {near }}\right.$ ). The "near" values are, by definition, lower than the "max" ones, but they are not necessarily correlated. Similarly, we calculated $r_{\mathrm{P}}$ between digestibility measured in the $\mathrm{A}_{\max }$ and $\mathrm{A}_{\text {near }}$ trials. We used the second approach of evaluating repeatability (ie, $r_{\mathrm{p}}$ ) because some individuals did not survive the trials at $-10^{\circ} \mathrm{C}$, and were not included in the first analysis, whereas others survived the trials, but achieved their $\mathrm{A}_{\max }$ or $\mathrm{C}_{\max }$ at -5 or $-15^{\circ} \mathrm{C}$. Moreover, this way of evaluating repeatability is commonly used in physiological studies (Hayes and Jenkins 1997). We also calculated $r_{\mathrm{P}}$ between the pairs of trials at $-10^{\circ} \mathrm{C}$, to check how the estimates of repeatability change when trials are separated in time.

Values of the traits measured might have been influenced by position of cages in the chamber (a constant for an individual) as well as an effect of selection group or replicate lines (see Swallow et al. 1998a). These effects could increase the variation among individuals, and consequently could lead to an overestimation of repeatability. Moreover, part of the repeatability of $A_{\max }$ and $\mathrm{C}_{\max }$ resulted presumably from a correlation between the traits and body mass. To adjust for these potential effects, we calculated repeatability based on residuals from regression or ANCOVA. We performed the analysis in four steps; additional variables were entered in subsequent regression or ANCOVA models to remove particular sources of among-individual variation. The correlation coefficients (repeatabilities) were calculated from: (1) Unadjusted values. (2) Residuals from regression including three variables describing position of an individual in a chamber: Rack (coded as -1 and +1 ), Shelf (coded as $-1.5,-0.5$, +0.5 and +1.5 ), and Shelf ${ }^{2}$. With that coding, the value predicted by the model was for an "average" place in the chamber. The quadratic term was added to account for a possible non-linear effect of the stratification of air temperature. (3) Residuals from an ANCOVA model including position in the chamber and the effect of Linetype (control vs selected lines) and effect of replicate lines nested within selection groups (Line within Linetype). (4) Residuals from ANCOVA including body mass and the variables included in model 3 . Because we had one male and one female from a family, the results for both sexes were not statistically independent. Therefore, all the above analyses were performed separately for males and females.

Commonly, an average of body mass measured at the beginning and at the end of a trial is used as the "body mass" covariate in regression or ANCOVA. In the present study, however, body mass changes during the cold exposure depended on the value of the measured traits $\left(C_{\max }, A_{\max }\right)$. Moreover, we performed a series of cold-exposure trials, and in each of those body mass changes could depend on the trait measured. A logical solution is to use body mass measured before the first cold exposure. This approach also circumvents the statistical problem associated with using residuals from regressions on different body masses (see Hayes and Shonkwiler 1996). To minimize errors in body mass measurement, we used an average of six body mass readings, obtained during 12 days preceding the first cold exposure, as a covariate in the ANCOVA. To show how the estimates of regression slopes and of repeatabilities depend on which body mass is used as a covariate, we also performed the analysis with body mass measured after cold acclimation at $+5^{\circ} \mathrm{C}$, and with body mass measured at the beginning of a particular trial.

Preliminary analysis indicated that results based on non-transformed and log-transformed values were very similar. Because power equations are generally used to describe the relation between body mass and metabolism, we present the analyses based on log-transformed body mass, food consumption, and energy assimilation. All analyses were performed with SYSTAT 6.0 for Windows (SPSS, Inc). In tables, $p=0.000$ indicate significance level $p<0.0005$. 


\section{Results}

\section{General description}

Of 146 individuals used, three died during the first trial at $-5^{\circ} \mathrm{C}$ and two individuals were injured by accident and were excluded from analysis. For 141 individuals ( 70 females, 71 males), results were available from at least two feeding trials at sub-zero temperatures after cold-acclimation (Table 1). Of those individuals, 63 females and 60 males survived all the trials at $-10^{\circ} \mathrm{C}$. However, only 54 females and 44 males survived two days at $-15^{\circ} \mathrm{C}$, and the trial was interrupted.

Position of cage in the chamber significantly influenced survival of the individuals, measured as a number of the last trial survived by an individual (Kruskal-Wallis test: $p=0.009$ in females, $p=0.023$ in males). Most of the individuals that died were located on the bottom shelf. However, the position did not significantly influence the temperature or trial at which $\mathrm{C}_{\max }$ or $\mathrm{A}_{\max }$ were achieved.

Body mass before the first cold-exposure trial averaged $25.2 \mathrm{~g}$ in females and $31.7 \mathrm{~g}$ in males (Table 1). In both sexes, body mass decreased significantly during the first exposure to $-5^{\circ} \mathrm{C}$, but it was continuously increasing in the following trials at $+5^{\circ} \mathrm{C}$ (Fig. 1). Later, the pattern depended on sex. In males, body mass slightly decreased in the first days after moving from +5 to $-5^{\circ} \mathrm{C}$, then stabilized at about $34.8 \mathrm{~g}$. At $-10^{\circ} \mathrm{C}$, average body mass of males decreased continuously, and at $-15^{\circ} \mathrm{C}$ it dropped below the initial body mass (Fig. 1). Females, however, increased body mass at $-5^{\circ} \mathrm{C}$ to about $30.2 \mathrm{~g}$, and were able to maintain approximately constant mass at $-10^{\circ} \mathrm{C}$ (Fig. 1).

Table 1 . Body mass, maximum food consumption $\left(\mathrm{C}_{\max }\right)$, maximum energy assimilation $\left(A_{\max }\right)$, and digestibility in the cold-exposed laboratory house mice.

\begin{tabular}{|c|c|c|c|c|}
\hline \multirow{2}{*}{ Trait } & \multicolumn{2}{|c|}{ Females $(n=70)$} & \multicolumn{2}{|c|}{ Males $(n=71)$} \\
\hline & Mean & SD & Mean & SD \\
\hline \multicolumn{5}{|l|}{ Body mass } \\
\hline before cold exposure (g) & 25.2 & 2.6 & 31.7 & 3.6 \\
\hline after acclimation at $5^{\circ} \mathrm{C}(\mathrm{g})$ & 28.5 & 2.4 & 34.1 & 3.3 \\
\hline at $\mathrm{C}_{\max }(\mathrm{g})$ & 28.9 & 2.4 & 32.8 & 2.9 \\
\hline at $\mathrm{A}_{\max }(\mathrm{g})$ & 28.9 & 2.4 & 32.9 & 2.9 \\
\hline $\mathrm{C}_{\max }$ (dry mass g/day) & 10.4 & 0.7 & 10.7 & 0.7 \\
\hline$A_{\max }(k J /$ day $)$ & 139 & 9.1 & 144 & 9.1 \\
\hline \multicolumn{5}{|l|}{ Digestibility at $A_{\max }$} \\
\hline dry mass $(\%)$ & 73.8 & 0.1 & 73.8 & 0.1 \\
\hline energy $(\%)$ & 77.9 & 0.1 & 77.9 & 0.1 \\
\hline
\end{tabular}


Food consumption (dry mass) at room temperature averaged $4.3 \mathrm{~g} /$ day (pooled average for the males and females which survived all the trials), and increased to only $7.5 \mathrm{~g}$ /day during the first exposure to $-5^{\circ} \mathrm{C}$ (Fig. 1). However, during the second exposure to $-5^{\circ} \mathrm{C}$, after an acclimation in $+5^{\circ} \mathrm{C}$, consumption averaged $9.8 \mathrm{~g} /$ day. During the final trial at $-5^{\circ} \mathrm{C}$, food consumption achieved $10.3 \mathrm{~g}$ /day and did not increase in the following trials at $-10^{\circ} \mathrm{C}$ or $-15^{\circ} \mathrm{C}$ (Fig. 1).

At room temperature, digestibility of dry mass averaged $74.9 \%$ and digestibility of energy averaged $78.9 \%$. In the trial in which $\mathrm{A}_{\max }$ was achieved, digestibilities were about $1 \%$ lower (Table 1 ). None of the effects examined (position in chamber, linetype, line, body mass) affected significantly the digestibility coefficient (Table 2 ). Although the differences in digestibility coefficient between particular trials were statistically significant, the differences were very small, and the pattern of changes of the rate of energy assimilation almost exactly followed that of food consumption. Therefore, in Fig. 1 we presented an axis of energy assimilation, but not separate data points, because the points would almost completely overlap the corresponding points for food consumption.

Maximum food consumption $\left(\mathrm{C}_{\max }\right)$ averaged $10.5 \mathrm{~g} /$ day and the maximum rates of energy assimilation $\left(\mathrm{A}_{\max }\right)$ averaged $141.5 \mathrm{~kJ} /$ day (Table 1). Both variables increased with body mass (Fig. 2). In females, variation among replicate lines was also significant $\left(\mathrm{C}_{\max }: p=0.011, \mathrm{~A}_{\max }: p=0.005\right)$, but in neither sex did selected and control lines differ significantly. When initial body mass $\left(\mathrm{M}_{\mathrm{b}}\right)$ or body mass after the cold acclimation at $+5^{\circ} \mathrm{C}\left(\mathrm{M}_{\mathrm{a}}\right)$ were used as covariates, none of the variables describing the position in chamber (Shelf, Shelf ${ }^{2}$, Rack) appeared

Table 2. The correlation between maximum cold-induced rate of food consumption and body mass changes observed during cold-exposure trials. The coefficients are partial correlations $(r)$, ie correlations between residuals from values predicted by ANCOVA models including the effects of position in chamber, lines, and initial body mass. Cumulative body mass changes were calculated as a difference between the mass at the end of a particular period and body mass before the first cold exposure.

\begin{tabular}{|c|c|c|c|c|c|}
\hline \multirow{2}{*}{ Period } & \multirow{2}{*}{ Sex } & \multicolumn{2}{|c|}{ Body mass changes } & \multicolumn{2}{|c|}{ Cumulative changes } \\
\hline & & $r$ & $p$ & $r$ & $p$ \\
\hline \multirow[t]{2}{*}{ First 3 days at $-5^{\circ} \mathrm{C}$} & $\mathrm{F}$ & 0.303 & 0.008 & & \\
\hline & M & 0.418 & 0.000 & & \\
\hline \multirow[t]{2}{*}{16 days at $+5^{\circ} \mathrm{C}$} & $\mathrm{F}$ & -0.023 & 0.570 & 0.255 & 0.045 \\
\hline & M & -0.225 & 0.114 & 0.081 & 0.423 \\
\hline \multirow[t]{2}{*}{12 days at $-5^{\circ} \mathrm{C}$} & $\mathrm{F}$ & 0.430 & 0.001 & 0.526 & 0.000 \\
\hline & M & 0.476 & 0.000 & 0.471 & 0.000 \\
\hline \multirow[t]{2}{*}{6 days at $-10^{\circ} \mathrm{C}$} & $\mathrm{F}$ & 0.375 & 0.004 & 0.648 & 0.000 \\
\hline & M & 0.368 & 0.005 & 0.609 & 0.000 \\
\hline
\end{tabular}




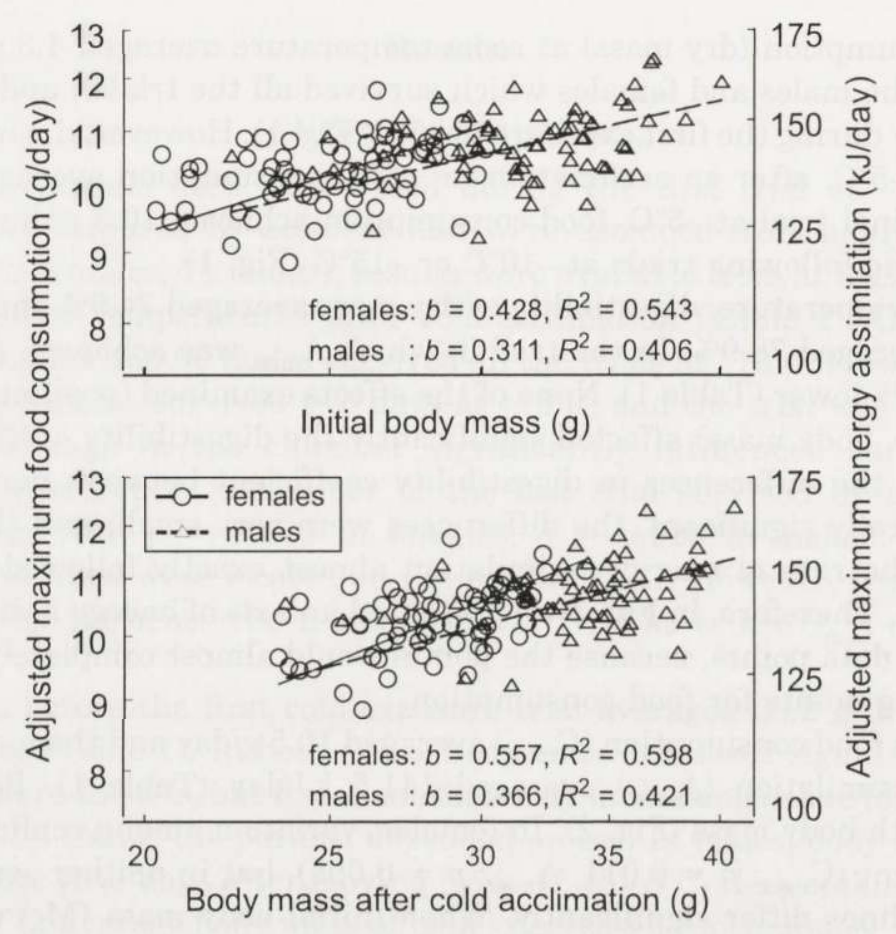

Fig. 2. Maximum cold-induced food consumption ( $\mathrm{g}$ dry mass/day) and energy assimilation ( $\mathrm{kJ} /$ day) in relation to body mass. The values are adjusted for the effects of position within chambers and differences among the lines (model 3 in Statistical Analysis section of Material and methods). The $b$ coefficients are common regression slopes from ANCOVA (model 4) with initial body mass (top) or body mass after cold-acclimation (bottom) as covariates. The values indicated by symbols are exact for food consumption, but only approximate for energy assimilation (the axis was scaled for an average digestibility). Note logarithmic scales.

significant in the ANCOVA models examined. However, when body mass measured in the trial at which $\mathrm{C}_{\max }$ was achieved $\left(\mathrm{M}_{\mathrm{m}}\right)$ was used as covariate, the model indicated that females on bottom shelves achieved higher rates of food consumption (effect of Shelf: $p=0.029$ ).

Body mass changes during all of the trials below $0^{\circ} \mathrm{C}$ depended on maximum rate of food consumption: individuals that achieved $\mathrm{C}_{\max }$ higher than expected from the ANCOVA model were losing less or gaining more mass than expected (Table 2). An opposite trend, although not statistically significant, appeared in the trials at $+5^{\circ} \mathrm{C}$, especially in males. Therefore, body mass measured after the first cold exposure, and in all the following trials, was not a trait independent of $\mathrm{C}_{\max }$ or $\mathrm{A}_{\max }$. The correlation between maximum consumption and body mass changes should lead to an increased range of body size after the cold exposure. This effect is not clear in Fig. 2 because body mass changes in the cold-exposure trials depended also on 
initial body mass: larger animals tended to lose body mass, while the smaller ones tended to increase mass (the effect was significant only in some of the trials). Therefore, the variation of body mass values after the cold exposure was actually somewhat smaller than that for initial mass (Table 1). Nevertheless, when $\mathrm{C}_{\max }$ or $\mathrm{A}_{\max }$ were regressed on the mass measured after cold-exposure, slopes were higher and residual variance in $\mathrm{C}_{\max }$ and $\mathrm{A}_{\max }$ was lower (higher $R^{2}$ ) than with initial mass as a covariate (Fig. 2).

\section{Estimation of repeatability}

Repeatability of log-transformed, unadjusted maximum food consumption, measured as intraclass correlation coefficient $\left(r_{\mathrm{i}}\right)$ among the trials at $-10^{\circ} \mathrm{C}$, was 0.786 in females and 0.807 in males (Table 3 ). Removing the effect of position in the chamber did not substantially decrease the coefficient. When the variation among

Table 3. Repeatability of log-transformed maximum food consumption $\left(\mathrm{C}_{\max }\right)$ and energy assimilation $\left(A_{\max }\right)$, and digestibility coefficient $\left(d_{p}\right)$ in cold-exposed mice. Repeatability was estimated as intraclass correlation coefficient $\left(r_{\mathrm{i}}\right)$ among three measurements performed at $-10^{\circ} \mathrm{C}(\mathrm{A})$, and as Pearson correlation coefficient $\left(r_{\mathrm{P}}\right)$ between the highest value achieved $\left(A_{\max }, C_{\max }\right)$ and a value in the trial next or previous to the one in which maximum was achieved (B). For digestibility, $r_{\mathrm{P}}$ was calculated from the values obtained in the $\mathrm{A}_{\max }$ trials. Body mass was entered in the model as either initial mass before cold exposure $\left(\mathrm{M}_{\mathrm{b}}\right)$, the mass after acclimation at $+5^{\circ} \mathrm{C}\left(\mathrm{M}_{\mathrm{a}}\right)$ or the mass at the beginning of a particular trial $\left(\mathrm{M}_{\mathrm{m}}\right)$. All correlation coefficients are significant at $p<0.001$, except those marked by an asterisk, which are significant at $p<0.005$.

\begin{tabular}{|c|c|c|c|c|c|}
\hline \multirow{3}{*}{ Trait } & \multirow{3}{*}{ Sex } & \multicolumn{4}{|c|}{ Based on } \\
\hline & & \multirow[t]{2}{*}{ Raw data } & \multicolumn{3}{|c|}{$\begin{array}{l}\text { Values controlled for the effects } \\
\text { of position, lines, and body mass }\end{array}$} \\
\hline & & & $\mathrm{M}_{\mathrm{b}}$ & $\mathrm{M}_{\mathrm{a}}$ & $\mathrm{M}_{\mathrm{m}}$ \\
\hline \multicolumn{6}{|l|}{$\mathrm{A} r_{\mathrm{i}}$} \\
\hline \multirow[t]{2}{*}{$\mathrm{C}_{\max }$} & $\mathrm{F}$ & 0.786 & 0.643 & 0.602 & 0.308 \\
\hline & M & 0.807 & 0.701 & 0.680 & 0.326 \\
\hline \multirow[t]{2}{*}{$A_{\max }$} & $\mathrm{F}$ & 0.777 & 0.621 & 0.574 & 0.239 \\
\hline & M & 0.795 & 0.658 & 0.635 & 0.261 \\
\hline \multirow[t]{2}{*}{$\mathrm{d}_{\mathrm{p}}$} & $\mathrm{F}$ & 0.353 & 0.261 & 0.259 & 0.252 \\
\hline & M & 0.546 & 0.422 & 0.420 & 0.409 \\
\hline \multicolumn{6}{|l|}{$\mathrm{B} r_{\mathrm{P}}$} \\
\hline \multirow[t]{2}{*}{$\mathrm{C}_{\max }$} & $\mathrm{F}$ & 0.895 & 0.820 & 0.787 & 0.707 \\
\hline & M & 0.867 & 0.785 & 0.768 & 0.743 \\
\hline \multirow[t]{2}{*}{$\mathrm{A}_{\max }$} & $\mathrm{F}$ & 0.894 & 0.825 & 0.791 & 0.625 \\
\hline & M & 0.837 & 0.748 & 0.727 & 0.684 \\
\hline \multirow[t]{2}{*}{$d_{p}$} & $\mathrm{~F}$ & $0.406^{*}$ & $0.440^{*}$ & $0.438^{*}$ & 0.451 \\
\hline & M & 0.679 & 0.598 & 0.602 & 0.586 \\
\hline
\end{tabular}


Table 4. Correlations between food consumption rates measured in three trials at $-10^{\circ} \mathrm{C}$, Residuals were calculated from ANCOVA including the effects of position in chamber and lines, and initial body mass as a covariate. All correlation coefficients are significant at $p<$ 0.001 . Trials 2 and 4 were separated by a 5 -day trial 3 , in which food consumption was not measured.

\begin{tabular}{lcccc}
\hline & & \multicolumn{3}{c}{ Days between trials } \\
\cline { 3 - 4 } Variable & Sex & 0 & 5 & 8 \\
\cline { 3 - 4 } & & trial $1 \times$ trial 2 & trial $2 \times$ trial 4 & trial $1 \times$ trial 4 \\
\hline Raw data & F & 0.754 & 0.846 & 0.771 \\
& M & 0.807 & 0.866 & 0.740 \\
Residuals & F & 0.587 & 0.787 & 0.680 \\
& M & 0.773 & 0.830 & 0.677 \\
\hline
\end{tabular}

lines was also controlled, $r_{\mathrm{i}}$ was 0.723 in females and 0.739 in males. Because $\mathrm{C}_{\max }$ depended on body mass, a considerable part of the repeatability resulted from consistent among-individual variation in body mass. However, the estimates of the repeatability of mass-independent consumption depended on which body mass was used in the model (Table 3). With body mass measured before cold exposure $\left(\mathrm{M}_{\mathrm{b}}\right), r_{\mathrm{i}}$ of mass-independent consumption was 0.643 in females and 0.701 in males. With body mass measured after cold acclimation at $+5^{\circ} \mathrm{C}\left(\mathrm{M}_{\mathrm{a}}\right)$, the repeatability was almost as high. However, with body mass measured at the trial at which $\mathrm{C}_{\max }$ was achieved $\left(\mathrm{M}_{\mathrm{m}}\right)$, the estimate of repeatability was much lower (Table 3). Nevertheless, all the values were highly significant (among-individual variation in one-way ANOVA: $p<0.0001)$. Among the trials at $-10^{\circ} \mathrm{C}$, the correlation $\left(r_{\mathrm{P}}\right)$ was highest between the second and fourth trial, separated by five days, rather than between the first two trials (Table 4).

Repeatability evaluated as a product-moment correlation $\left(r_{\mathrm{P}}\right)$ between $\mathrm{C}_{\max }$ and $\mathrm{C}_{\text {near }}$ (consumption in a trial next to that in which $\mathrm{C}_{\max }$ was achieved) was also very high (Table 3, Fig. 3). Repeatability of maximum energy assimilation was similar to that of food consumption, but the values appeared slightly lower in most of the models tested (Table 3). The rate of energy assimilation, however, was calculated with a common value of energy content in feces $\left(\mathrm{E}_{\text {feces }}\right)$. Thus, if the values of $\mathrm{E}_{\text {feces }}$ vary among individuals, then the actual repeatability of $\mathrm{A}_{\max }$ may be slightly higher than that estiamated here.

Repeatability $\left(r_{\mathrm{i}}\right)$ of digestibility of food in the cold-exposure trials was higher in males $(0.546)$ than in females $(0.353$; Table 3$)$. Repeatability was almost the same when calculated from the mass- and position-adjusted values. With variation among lines removed, however, repeatability was 0.428 in males and 0.266 in females. Repeatabilities for digestibility of energy were the same because digestibility was calculated using a common value of energy content of feces. Although 

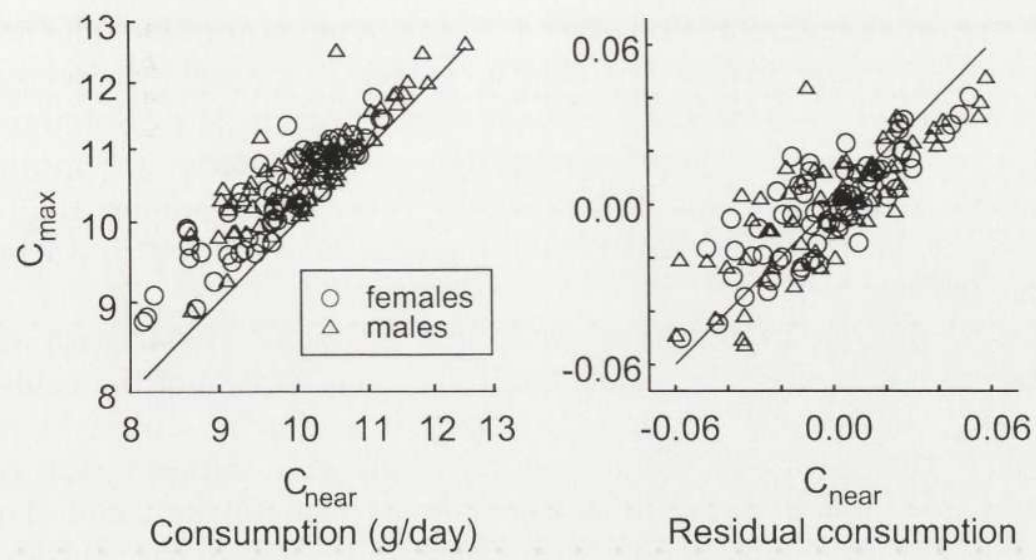

Fig. 3. Correlation between maximum cold-induced rate of food consumption $\left(\mathrm{C}_{\max }\right)$ and food consumption rate in a trial next or previous to that in which $\mathrm{C}_{\max }$ was achieved $\left(\mathrm{C}_{\text {near }}\right)$. Left: non-adjusted values (log scale), right: residuals from ANCOVA (log-transformed values adjusted for the effect of position in chamber, line, and initial body mass). Solid lines indicate 1:1 relationship. The values of the coefficients of correlation and significance levels are presented in Table 3.

the repeatability of digestibility was lower than that for food consumption, it was still highly significant $(p<0.001)$. Repeatability measured as a Pearson correlation $\left(r_{\mathrm{P}}\right)$ between the values in the $\mathrm{A}_{\max }$ and $\mathrm{A}_{\text {near }}$ trials was also highly statistically significant (Table 3).

\section{Discussion}

The pattern of changes of body mass and food consumption in the consecutive trials (Fig. 1) demonstrates clearly that the mice did achieve a maximum cold-induced level of food consumption and energy assimilation. The maximum rate of food consumption in females ( $10.4 \mathrm{~g} /$ day) was slightly higher than that measured by Konarzewski and Diamond (1994; about $10 \mathrm{~g}$ /day) in females of a similar outbred strain of laboratory mice (Swiss-Webster). Caloric content of the food used in the present study was, however, lower than that in Konarzewski and Diamond (1994), and the maximum rates of energy assimilation were almost exactly the same (139 $\mathrm{kJ} /$ day). On the other hand, the pattern of body mass changes was remarkably different. The females used by Konarzewski and Diamond (1994) were larger (initial mass: $30-42 \mathrm{~g}$ ), and they were losing body mass at $0^{\circ} \mathrm{C}$ and lower ambient temperatures. In the present study, the initial mass of females was only $25 \mathrm{~g}$, but they were gaining body mass at $-5^{\circ} \mathrm{C}$ and they were able to maintain mass at $-10^{\circ} \mathrm{C}$. The difference between our studies might result from differences in age or initial body composition. The mice used by Konarzewski and Diamond (1994) were older 
(120-140 days of age), and initially had a very high amount of fat. The decrease in body mass at low temperatures was almost exclusively caused by a decrease in fat content, while the lean body mass was constant of about $24 \mathrm{~g}$ (Konarzewski and Diamond 1994: Fig. 1). In the present study, mice had access to running wheels since weaning, and it may be assumed that they were lean (Swallow 1998: Chapter V). We speculate that, when exposed to low temperatures, they were storing, rather than using, fat reserves.

Our study differed from Konarzewski and Diamond (1994) with respect to housing of the mice before the trials, quality of food, details of the cold-exposure protocol, and the pattern of body mass changes during the cold exposure. Nevertheless, the estimated values of maximum cold-induced rate of energy assimilation in cold-acclimated mice were almost exactly the same. This result suggests that the cold-exposure protocol including a long-term cold acclimation allows measurement of a trait that is repeatable across independent studies and laboratories, unlike measurement of some behavioral traits (Crabbe et al. 1999), and that the estimate is robust with respect to some details of the protocol. This observation is fundamental to initiation of comparative studies on the limits to energy budgets.

The measurements of $\mathrm{A}_{\max }$ and $\mathrm{C}_{\max }$ were also highly repeatable at the level of individual variation. The repeatability measured as a product-moment correlation coefficient $\left(r_{\mathrm{P}}\right)$ between adjacent trials (Table 3, Fig. 3 ) was as high as the repeatability of maximum oxygen consumption estimated in two species of rodents (Hayes 1989a, b, Hayes and Chappell 1990, Chappell et al. 1995), in lizards (Garland and Else 1997), snakes (Garland and Bennett 1990), and in fowl (Chappell et al. 1996). Repeatability measured as an intraclass correlation among the values obtained in three trials at $-10^{\circ} \mathrm{C}$ was also very high $(0.64-0.70$; based on mass- -independent values calculated with initial mass), much higher than the repeatability of average daily energy expenditures measured in two species of rodents (about 0.26-0.27; Speakman et al. 1994, Bertaux et al. 1996). A comparison of three correlation coefficients $\left(r_{\mathrm{P}}\right)$ between pairs of the trials at $-10^{\circ} \mathrm{C}$ indicates also that the repeatability does not decrease rapidly when the trials are separated in time by several days (Table 4). Position in the chamber, associated with different thermal conditions, did affect the chance of survival of the individuals, but did not affect significantly the maximum rate of food consumption achieved by the individuals. This again indicates that the estimates of $\mathrm{C}_{\max }$ and $\mathrm{A}_{\max }$ in animals that undergo a long-term cold-acclimation are robust with respect to some variation in the measurement protocol. Thus, the values of the maximum cold-induced food consumption and energy assimilation are reliable estimates of the performance of individuals under a specific environmental condition, namely low ambient temperature, but not limited access to food. The estimates of coefficient of digestibility were also repeatable (Table 3), which indicates consistent among-individual differences in the efficiency of food digestion or nutrient absorption. 
Two caveats should be kept in mind. First, our study cannot answer the question whether high repeatability of $\mathrm{C}_{\max }$ and $\mathrm{A}_{\max }$ would persist over longer time scales, approaching the lifespan of the mice. Perhaps performance changes during ontogeny and the age-dependence of performance varies among individuals. If so, then repeatability would inevitably decrease.

Second, our study indicates that the estimate of repeatability of mass-independent values can vary dramatically depending on which estimate of body mass is used as a covariate. Body mass measured after the cold acclimation $\left(\mathrm{M}_{\mathrm{a}}\right)$, or in the trial at which $\mathrm{C}_{\max }$ or $\mathrm{A}_{\max }$ was achieved $\left(\mathrm{M}_{\mathrm{m}}\right)$, depended on $\mathrm{A}_{\max }$ or $\mathrm{C}_{\max }$, because the individuals with higher than expected maximum consumption were gaining more or losing less mass than those with lower maxima (Table 2). The regression slopes based on the body mass measured after cold-exposure were steeper than those with initial body mass as a covariate. More importantly, the models based on $\mathrm{M}_{\mathrm{a}}$ or $\mathrm{M}_{\mathrm{m}}$ explained more variance, as indicated by higher coefficients of determination (Fig. 2). In other words, during the cold-exposure trials, part of the existing inter-individual variation in $\mathrm{C}_{\max }$ or $\mathrm{A}_{\max }$ converts into variation in body mass. Not surprisingly, then, this leads to a decreased estimate of repeatability of the residuals from the models based on the resulting body mass. In this situation, it is not obvious which of the estimates of the repeatability of a "mass-independent" trait is most relevant. If the changes of body mass during the cold exposure were caused primarily by changes in fat content, as in Konarzewski and Diamond (1994), then the initial body mass seems to be the best choice. However, if the body mass changes resulted from changes in the size of certain internal organs, which themselves may limit the rate of energy processing, then the situation is unclear. In this case, the choice of the appropriate covariate may depend on the specific question asked (for a similar conclusion, see Christians 1999).

Questions about the proximate physiological mechanisms limiting energy budgets have been a subject of vivid discussion (eg Peterson et al. 1990, Dykstra and Karasov 1992, Weiner 1992, Hammond et al. 1994, Konarzewski and Diamond 1994, McDevitt and Speakman 1994, Koteja 1996a, b, Hammond and Diamond 1997). However, whatever the physiological mechanism, limitation by physiological rather than environmental factors may be common in small mammals and birds (Weiner 1987, Masman et al. 1989, Hammond and Diamond 1997). Therefore, $C_{\max }$ and $\mathrm{A}_{\max }$ may be subject to phenotypic natural selection. Whether such selection may result in an evolutionary change remains an open question, because narrow-sense heritability has not been determined. Nevertheless, highly significant repeatability and significant variation among the replicate lines suggests that some of the observed variation in maximum food consumption and energy assimilation is indeed genetically based.

Acknowledgements: This project was supported by grants from the U.S. National Science Foundation (IBN-9111185, IBN-9157268, and IBN-9728434) to T. Garland, and by the University of Wisconsin Graduate School. P. Koteja was supported by stipends from the Foundation for Polish Science and from Jagiellonian University. We thank W. H. Karasov for use of the bomb calorimeter, and J. Weiner and three anonymous reviewers for critical comments on the manuscript. 


\section{References}

Bennett A. F. 1997. Adaptation and the evolution of physiological characters. [In: Handbook of physiology. Vol. I. W. H. Dantzler, ed]. Oxford University Press, New York: 3-16.

Berteaux D., Thomas D. W., Bergeron J.-M. and Lapierre H. 1996. Repeatability of daily field metabolic rate in female meadow voles (Microtus pennsylvanicus). Functional Ecology 10: 751-759.

Boake C. R. B. 1989. Quantitative genetic studies of behavioral evolution. University of Chicago Press, Chicago: 1-390.

Carter P. A., Garland T. Jr, Dohm M. R. and Hayes J. P. 1999. Genetic variation and correlations between genotype and locomotor physiology in outbred laboratory house mice (Mus domesticus). Comparative Biochemistry and Physiology A 123: 157-164.

Chappell M. A., Bachman G. C. and Odel J. P. 1995. Repeatability of maximal aerobic performance in Belding's ground squirrels, Spermophilus beldingi. Functional Ecology 9: 498-504.

Chappell M. A., Zuk M. and Johnsen T. S. 1996. Repeatability of aerobic performance in red junglefowl: effects of ontogeny and nematode infection. Functional Ecology 10: 578-585.

Christians J. K. 1999. Controlling for body mass effects: is part-whole correlation important? Physiological and Biochemical Zoology 72: 250-253.

Crabbe J. C., Wahlsten D. and Dudek B. C. 1999. Genetics of mouse behavior: interactions with laboratory environment. Science 284: 1670-1672.

Dohm M. R. 1994. Quantitative genetics of locomotor performance and physiology in house mice Mus domesticus). $\mathrm{Ph} \mathrm{D}$ thesis, University of Wisconsin, Madison: 1-XV+264.

Dohm M. R., Hayes J. P. and Garland T. Jr 1996. Quantitative genetics of sprint running speed and swimming endurance in laboratory house mice (Mus domesticus). Evolution 50: 1688-1701.

Drożdż A. 1975. Metabolic cages for small mammals. [In: Methods for ecological bioenergetics. IBP Handbook no. 24. W. Grodziński, R. Z. Klekowski and A. Duncan, eds]. Blackwell Scientific Publications, Oxford: 346-351.

Dykstra C. R. and Karasov W. H. 1992. Changes in gut structure and function of house vrens (Troglotydes aedon) in response to increased energy demand. Physiological Zoology 65: 422-442.

Falconer D. S. and Mackay T. F. C. 1996. Introduction to quantitative genetics. 4th ed. Longman, Essex: 1-464.

Feder M. E., Bennett A. F. and Burggren W. W. 1987. New directions in ecological physidogy. Cambridge University Press, New York: 1-364.

Garland T. Jr and Bennett A. F. 1990. Quantitative genetics of maximal oxygen consumption in a garter snake. American Journal of Physiology 259: R986-R982.

Garland T. Jr and Carter P. A. 1994. Evolutionary physiology. Annual Review of Physiologr 56: 579-621.

Garland T. Jr and Else P. L. 1987. Seasonal, sexual, and individual variation in endurance and acivity metabolism in lizards. American Journal of Physiology 252: R439-R449.

Hammond K. A. and Diamond J. 1994. Limits to dietary nutrients intake and intestinal nutrient uptake in lactating mice. Physiological Zoology 67: 282-303.

Hammond K. A. and Diamond J. 1997. Maximal sustained energy budgets in humans and aninals. Nature 386: 457-462.

Hammond K. A., Konarzewski M., Torres R. M. and Diamond J. 1994. Metabolic ceilings under a combination of peak energy demands. Physiological Zoology 67: 1479-1506.

Hauschka T. S. and Mirand E. A. 1973. The "breeder: HA(ICR)" Swiss mouse, a multipurpose stock selected for fecundity. [In: Perspectives in cancer research and treatment. G. P. Murph, D. Pressman and E. A. Mirand, eds]. Alan R. Riss, Inc., New York: 319-331.

Hayes J. P. 1989a. Altitudinal and seasonal effects on aerobic metabolism of deer mice. Jourral of Comparative Physiology B 159: 453-459.

Hayes J. P. 1989b. Field and maximal metabolic rates of deer mice (Peromyscus maniculatus) a low and high altitudes. Physiological Zoology 62: 732-744. 
Hayes J. P. and Chappell M. A. 1986. Effects of cold acclimation on maximum oxygen consumption during cold exposure and treadmill exercise in deer mice, Peromyscus maniculatus. Physiological Zoology 59: 473-481.

Hayes J. P. and Chappell M. A. 1990. Individual consistency of maximal oxygen consumption in deer mice. Functional Ecology 4: 495-503.

Hayes J. P., Garland T. Jr. and Dohm M. R. 1992. Individual variation in metabolism and reproduction of Mus: are energetics and life history linked? Functional Ecology 6: 5-14.

Hayes J. P. and Jenkins S. H. 1997. Individual variation in mammals. Journal of Mammalogy 78 : 274-293.

Hayes J. P. and O'Connor C. S. 1999. Natural selection on thermorgenic capacity of high-altitude deer mice. Evolution 53: 1280-1287.

Hayes J. P. and Shonkwiler J. S. 1996. Analyzing mass-independent data. Physiological Zoology 69: 974-980.

Karasov W. H. 1990. Digestion in birds: chemical and physiological determinants and ecological implications. Studies in Avian Biology 13: 391-415.

Kolok A. S. 1999. Interindividual variation in the prolonged locomotor performance of ectothermic vertebrates: a comparison of fish and herpetofaunal methodologies and a brief review of the recent fish literature. Canadian Journal of Fisheries and Aquatic Sciences 56: 700-710.

Konarzewski M. and Diamond J. 1994. Peak sustained metabolic rate and its individual variation in cold-stressed mice. Physiological Zoology 67: 1186-1212.

Koteja P. 1995. Maximum cold-induced energy assimilation in a rodent, Apodemus flavicollis. Comparative Biochemistry and Physiology 112 A: 479-485.

Koteja P. 1996a. Limits to the energy budget in a rodent, Peromyscus maniculatus: the central limitation hypothesis. Physiological Zoology 69: 981-993.

Koteja P. 1996b. Limits to the energy budget in a rodent, Peromyscus maniculatus: does gut capacity set the limit? Physiological Zoology 69: 994-1020.

Koteja P., Garland T. Jr, Sax J. K., Swallow J. G. and Carter P. A. 1999a. Behaviour of house mice artificially selected for high levels of voluntary wheel running. Animal Behaviour 58: 1307-1318.

Koteja P., Król E. and Staliński J. 1994. Maximum cold- and lactation induced rate of energy assimilation in Acomys cahirinus. Polish Ecological Studies 20: 369-374.

Koteja P., Swallow J. G., Carter P. A. and Garland T. Jr 1999b. Energy cost of wheel running in house mice: implications for coadaptation of locomotion and energy budgets. Physiological and Biochemical Zoology 72: 238-249.

Lessells C. M. and Boag T. 1987. Unrepeatable repeatabilities: a common mistake. Auk 104: 116-121.

Masman D., Dijkstra C., Daan S. and Bult A. 1989. Energetic limitation of parental effort: field experiments in the kestrel (Falco tinnunculus). Journal of Evolutionary Biology 2: 435-455.

McDevitt R. M. and Speakman J. R. 1994. Central limits to sustainable metabolic rate have no role in cold acclimation of the short-tailed field vole (Microtus agrestis). Physiological Zoology 67: $1117-1139$.

Peterson C. C., Nagy K. A. and Diamond J. 1990. Sustained metabolic scope. Proceedings of the National Academy of Science USA 87: 2324-2328.

Rice M. C. and O'Brien S. J. 1980. Genetic variance of laboratory outbred Swiss mice. Nature 283: 157-161.

Sokal R. R. and Rohlf F. J. 1981. Biometry. 2nd ed. Freeman, San Francisco: 1-859.

Speakman J. R. and McQueenie J. 1996. Limits to sustained metabolic rate: the link between food intake, basal metabolic rate, and morphology in reproducing mice, Mus musculus. Physiological Zoology 69: 746-769.

Speakman J. R., Racey P. A., Haim A., Webb P. I., Ellison G. T. H. and Skinner J. D. 1994. Inter- and intraindividual variation in daily energy expenditure of the pouched mouse (Saccostomus campestris). Functional Ecology 8: 336-342.

Swallow J. G. 1998. Artificial selection for high voluntary activity in house mice: a study in evolutionary physiology. University of Wisconsin, Madison: 1-179. 
Swallow J. G., Carter P. A. and Garland T. Jr 1998a. Artificial selection for increased wheel-running behavior in house mice. Behavior Genetics 28: 227-237.

Swallow J. G., Garland T. Jr, Carter P. A., Zhan W.-Z. and Sieck G. C. 1998b. Effects of voluntary activity and genetic selection on aerobic capacity in house mice (Mus domesticus). Journal of Applied Physiology 84: 69-76.

Weiner J. 1987. Maximum energy assimilation rates in the Djungarian hamster (Phodopus sungorus). Oecologia (Berlin) 72: 297-302.

Weiner J. 1989. Metabolic constraints to mammalian energy budgets. Acta Theriologica 34: 3-35.

Weiner J. 1992. Physiological limits to sustainable energy budgets in birds and mammals: ecological implications. Trends in Ecology and Evolution 7: 384-388.

Received 21 July 1999, accepted 7 March 2000. 